\title{
Qualidade do Sistema de Abastecimento de Água do Bairro Olaria, Município de Corrente, Piaú (Nordeste do Brasil)*
}

Tancio Gutier Ailan Costa ${ }^{1}$, Gleide Ellen dos Santos Clementino ${ }^{1}$, Larissa do Nascimento Serpa ${ }^{1}$, Nayara Caroline Moreira Leopoldoํㅡㄹ Juliana Vogado Coelho ${ }^{1}$, Israel Lobato Rocha ${ }^{2}$

${ }^{1}$ Discente. Curso de Tecnologia em Gestão Ambiental. Instituto Federal de Educação, Ciência e Tecnologia do Piaú. Rua Projetada 06, 380. Nova Corrente. Corrente-PI (CEP 64980-000).

${ }^{2}$ Docente. Curso de Tecnologia em Gestão Ambiental. Instituto Federal de Educação, Ciência e Tecnologia do Piauí. Rua Projetada 06, 380. Nova Corrente. Corrente-PI (CEP 64980-000). E-mail: israel.lobato@ifpi.edu.br.

Resumo. A condição básica necessária à água distribuída para o consumo humano é a potabilidade, ou seja, deve ser tratada, limpa e estar livre de qualquer contaminação, seja esta de origem microbiológica, química, física ou radioativa, não devendo, em hipótese alguma, oferecer riscos à saúde humana. Neste contexto, este trabalho teve como objetivo analisar a percepção dos moradores do Bairro Olaria quanto à qualidade do sistema de abastecimento de água do Município de Corrente-PI. A metodologia empregada se deu através da aplicação de questionário previamente elaborado contendo questões fechadas, com o intuito de detectar os anseios e opiniões dos moradores do bairro. O estudo verificou que os moradores possuem uma percepção apurada e consciente sobre a qualidade da água, pois estes acreditam que a água consumida no bairro possui pouca qualidade para o consumo. Desta forma alguns aspectos de análises da água apontam que em alguns pontos do sistema de abastecimento, esta qualidade da água não atende aos padrões de potabilidade, evidenciando o questionamento dos moradores quanto ao sistema de abastecimento de água que é distribuída ao Bairro Olaria.

Palavras-chave: Água potável; Percepção social; Qualidade da água.

Abstract: Quality of the water supply system of Olaria neighborhood, Municipality of Corrente, State of Piauí (Northeast Brazil). The basic condition required for water distribution for human consumption is that it is drinkable. It should be treated, cleaned and be free of any contamination, whether microbiological origin, chemical, physical or radioactive and it should not, under any circumstances, offer risks to human health. In this context, this study aimed at analyzing the perception of the residents of the Olaria neighborhood on the quality of the Corrente municipal water supply system. The methodology used was the previously prepared questionnaire with closed questions, in order to detect the concerns and opinions of neighborhood residents. The study found that

Recebido:

$17 / 11 / 2015$

Aceito:

27/03/2016

Publicado:

$30 / 06 / 2016$

Acesso Aberto

Artigo completo

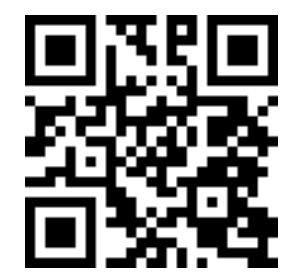

ORCIID

(D) 0000-0002-0635-2651

Tancio Gutier Ailan Costa

(D) 0000-0001-5264-8499

Gleide Ellen dos Santos Clementino

Cㄱ $0000-0002-8560-4393$

Larissa do Nascimento Serpa

(- 0000-0002-0979-0657

Nayara Caroline

Moreira Leopoldo

D 0000-0003-2029-9997

Juliana Vogado Coelho

*Apresentado no Congresso Brasileiro de Gestão Ambiental e Sustentabilidade - Congestas 2015, João Pessoa-PB, 9 a 11 de dezembro de 2015. 
residents have an accurate awareness about water quality, because they believe that the water consumed in the neighborhood has poor quality for consumption. Thus some aspects of the water analyzed indicate that in some parts of the supply system, this water quality does not meet the drinkability standards, showing the questioning of the residents as to the water supply system that distributes water to the Olaria neighborhood.

Keywords: Drinkable water; Social perception; Water quality.
0000-0002-4496-9935

Israel Lobato Rocha

\section{Introdução}

A situação atual dos recursos hídricos aponta para um quadro de crise (MMA, 2009). No continente americano, há água abundante em algumas regiões, enquanto em outras esse recurso pode ser escasso, sendo a urbanização um dos processos que têm causado impacto tanto nas águas superficiais quanto nas águas subterrâneas (Cisneros e Tundisi, 2012).

A qualidade necessária à água distribuída para consumo humano é a potabilidade, ou seja, deve ser tratada, limpa e estar livre de qualquer contaminação, seja esta de origem microbiológica, química, física ou radioativa, não devendo, em hipótese alguma, oferecer riscos à saúde humana (Brasil, 2004). Essa potabilidade é alcançada mediante várias formas de tratamento, sendo que a mais tradicional inclui basicamente as etapas de coagulação, floculação, decantação, filtração, desinfecção e a fluoretação (Freitas, 2002).

De acordo com Magalhães (2012), a disponibilidade de água potável ao consumo do ser humano pode ser considerada o principal fator à sobrevivência e à melhoria da qualidade de vida das populações rurais, sobretudo nas regiões áridas e semiáridas. Principalmente quando se examinam a precariedade do sistema de abastecimento de água, de esgotos sanitários, de destinação do lixo, a ausência ou insuficiência de medidas de proteção contra os níveis de poluição e contaminação hídrica.

Portanto, o melhoramento nos serviços públicos de abastecimento de água reflete numa melhoria na saúde da população (Libânio et al., 2005), já que a água é um recurso natural essencial à manutenção da vida. Além disso, são necessários alguns cuidados em relação ao uso, à qualidade, às fontes, além de planejamento e custeio de tratamento, de conservação e proteção.

No Município de Corrente, situado na Região Sul do Estado do Piauí, o tratamento aplicado à água de abastecimento é do tipo convencional, processo compreendido pelas operações unitárias de coagulação, floculação, decantação, e filtração para a clarificação da água, seguida da correção do $\mathrm{pH}$, desinfecção e fluoretação. Contudo, o acesso à rede de abastecimento público e água tratada muitas vezes não garante a qualidade da água recebida, uma vez que este pode ser realizado de maneira imprópria fugindo dos padrões estabelecidos pela legislação.

Neste contexto, este trabalho teve como objetivo analisar a percepção dos moradores do Bairro Olaria quanto à qualidade do Sistema de Abastecimento de Água do Município de Corrente-PI.

\section{Material e métodos}

$\mathrm{O}$ estudo foi realizado no Município de Corrente, (10 26’36” S; $45^{\circ} 09^{\prime} 44^{\prime \prime} \mathrm{W}$ ), situa-se a $864 \mathrm{~km}$ da capital do estado Teresina com área de 3045,9 km² (Figura 1) com sua população de 25.407 habitantes. O município localizase no bioma Cerrado, com clima tropical semiúmido e período chuvoso concentrado principalmente entre os meses de fevereiro a abril. 


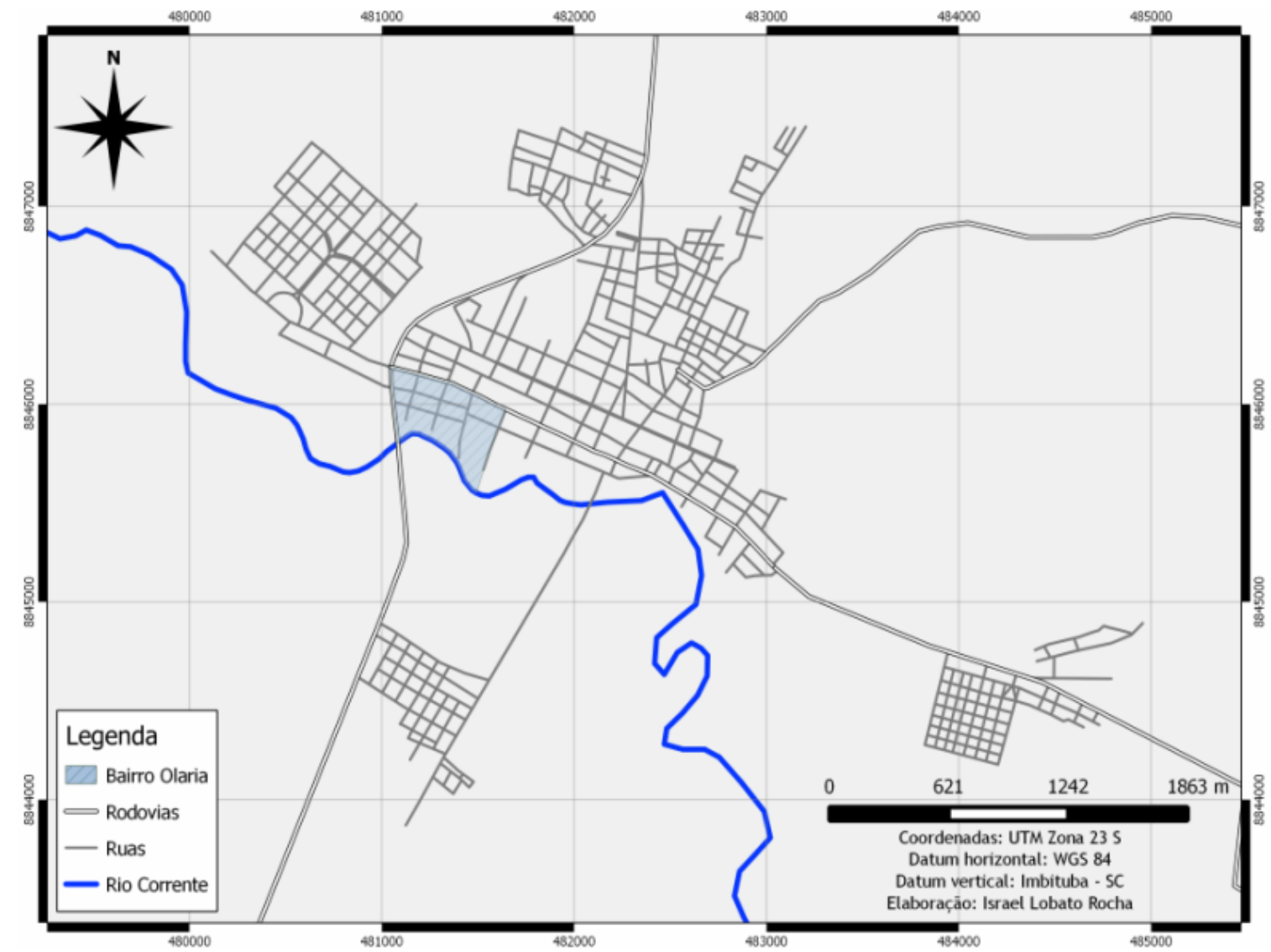

Figura 1. Localização do Bairro Olaria, no Município de Corrente, Piauí.

A pesquisa foi desenvolvida no Bairro Olaria, tendo como metodologia empregada a aplicação de questionário previamente elaborado contendo questões fechadas, com o intuito de detectar os anseios e opiniões dos moradores do bairro. Para analise e tabulação dos dados foram utilizados softwares como o Excel, e o método da contagem para as perguntas fechadas em que a partir disso foram elaborados os gráficos para representação dos percentuais das respostas vigentes nos questionários. A metodologia adotada para identificação do universo amostral dos moradores a serem entrevistados foi quanto às técnicas de amostragem de Cochran (1965).

\section{Resultados e discussão}

\section{Perfil socioeconômico dos entrevistados \\ O estudo traçou inicialmente os} perfis dos usuários entrevistados, conforme indicado na Figura 2a, no qual se observou que da população amostral envolvida são em maior número do sexo feminino e a faixa etária dos entrevistados corresponde em sua maioria entre 31 a 40 anos (Figura 2b). A renda familiar dos entrevistados compreende a faixa de 1 a 2 salários mínimos, sendo que grande parte dos moradores possuem apenas ensino médio. 


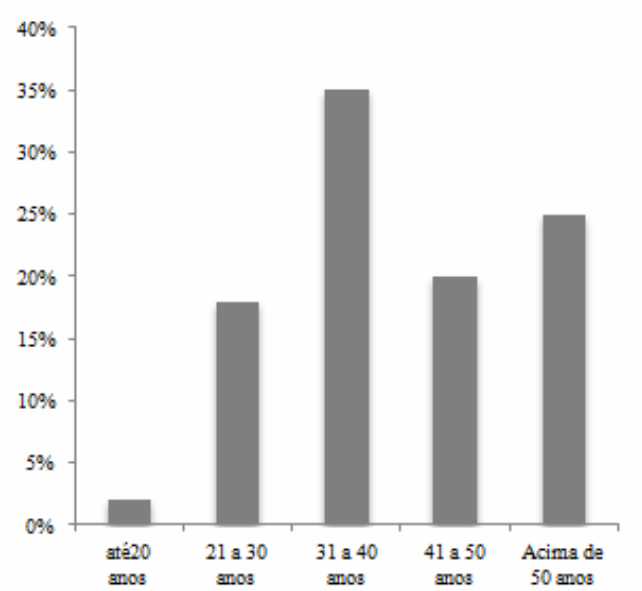

(a)

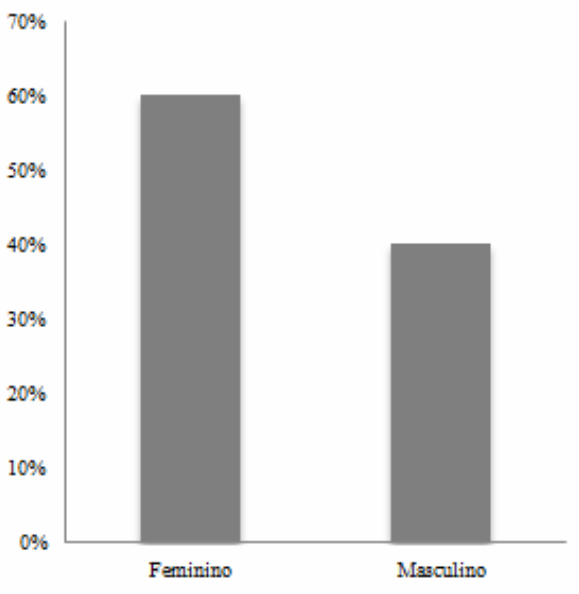

(b)

Figura 2. Perfil dos entrevistados quanto à faixa etária (a) e gênero (b).

\section{Percepção da qualidade da água}

No que se refere à percepção dos moradores sobre a qualidade da água consumida no bairro, quando questionados sobre a procedência da água do qual fazem uso, percebeu-se que a maioria dos entrevistados (89\%) indicou que tem procedência direta do principal rio da cidade e apenas uma pequena parcela dos entrevistados (11\%) relataram a Estação de Tratamento de Água situada no município (Figura 3). Diante disso fica evidente que a população envolvida possui pouco conhecimento sobre o processo de captação e distribuição da água da qual fazem uso.

A qualidade da água reflete diretamente sobre o bem estrar da população e aslubridade ambiental. Assim foram questionados aos moradores sobre o grau de percepção sobre a qualidade da água distribuída ao Bairro Olaria, no qual $40 \%$ dos entrevistados indicaram como ruim a qualidade da água de abastecimento e apenas 5\% destes apontaram como ótima a situação atual da qualidade da água (Figura 4).

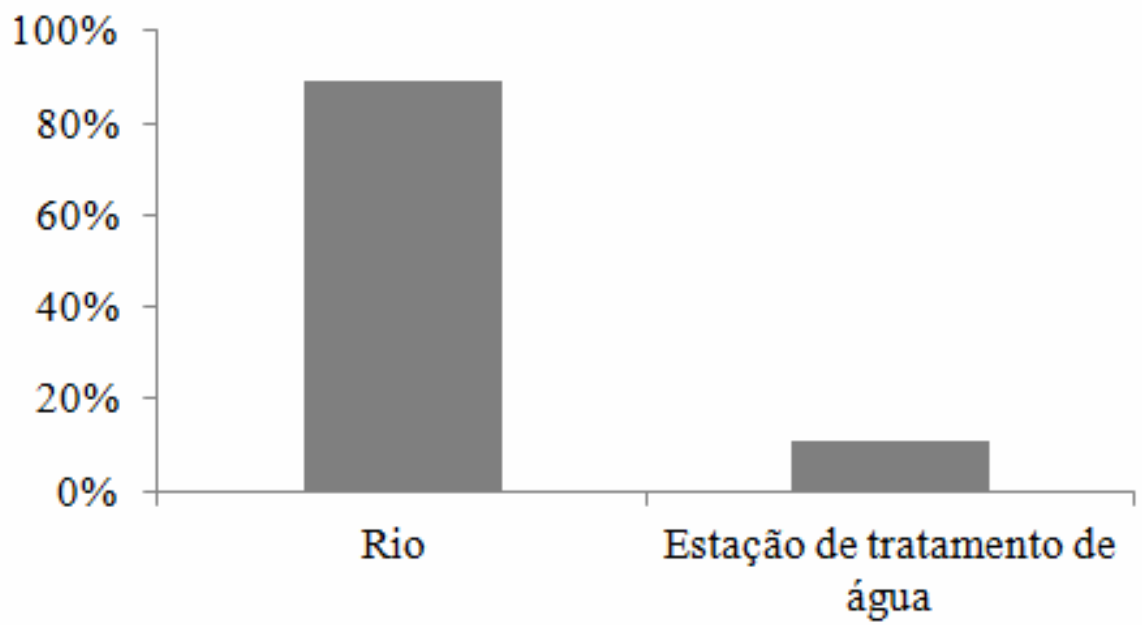

Figura 3. Procedência da água de abastecimento do Município de Correntes-PI. 


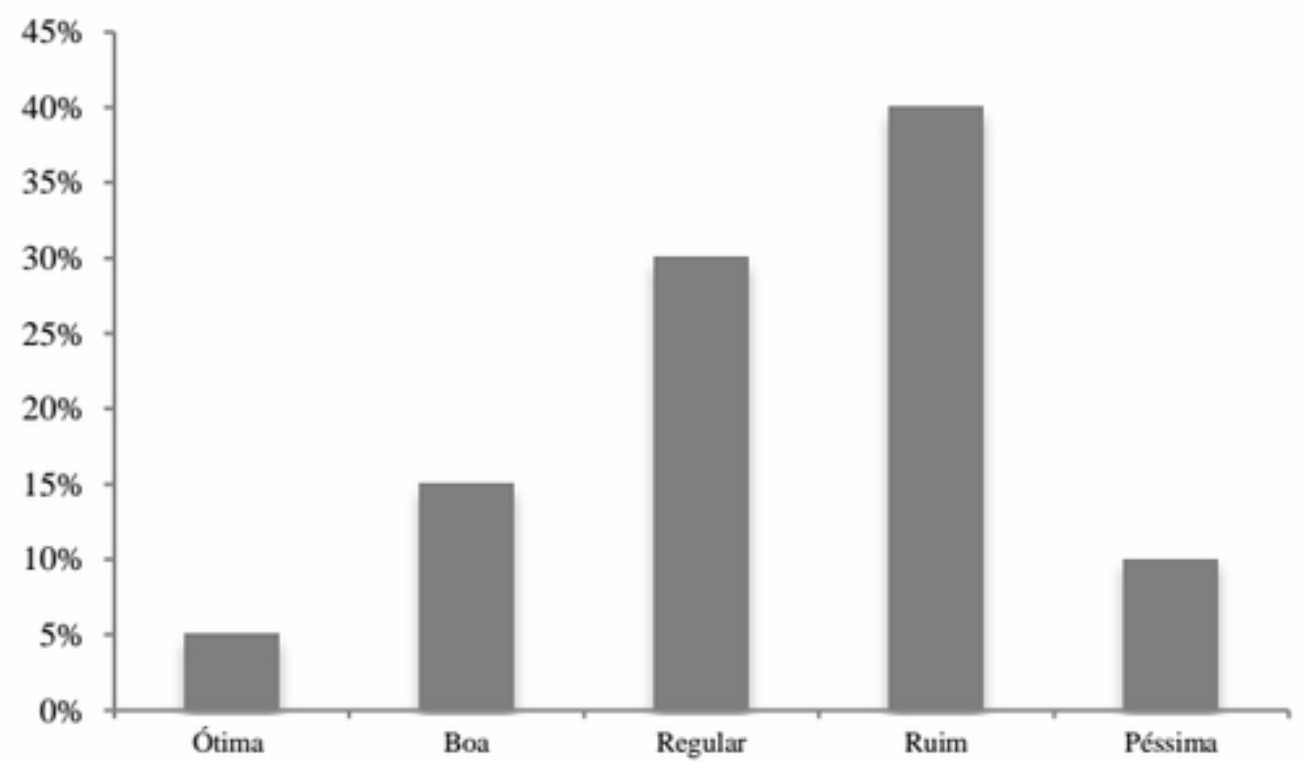

Figura 4. Grau de percepção da qualidade da água dos entrevistados do Município de Correntes-PI.

Considerando que somente um parâmetro não pode mensurar especificamente a qualidade da água, a situação e descrição feita pelos moradores da cidade demonstram a insatisfação a respeito do sistema de fornecimento e abastecimento de água da cidade, principalmente do bairro em questão.

Os serviços públicos de abastecimento devem sempre fornecer água de boa qualidade, através de realizações de análise e exames das águas que são distribuídas para a cidade (Richter e Azevedo Netto, 1991). Assim perguntaram-se aos moradores envolvidos na pesquisa sobre qual fator eles consideravam como sendo o mais importante para manter os padrões de qualidade da água entre tratamento, manutenção e percurso feito pela água (Figura 5a).

Dos entrevistados 58\% apontaram a forma de tratamento como o principal responsável pelo aspecto de qualidade da água e apenas $2 \%$ indicaram a opção outro, pela questão de não ter conhecimento dos processos adotados pela estação de tratamento (Figura 5).

Os entrevistados foram questionados quanto ao critério que poderia indicar a qualidade da água, conforme sua percepção. A Figura 5b indica que $60 \%$ dos entrevistados avalia a qualidade da água pela cor, $30 \%$ avalia conforme o sabor e $10 \%$ considera o odor como critério de qualidade da água.

Os aspectos de qualidade da água, a sua tendência e permanecia de qualidade, preservação e as condições de segurança aos indivíduos que dela fazem uso, são critérios importantes que devem estar relacionados às opiniões dos moradores. Desta forma, quanto à qualidade da água consumida $54 \%$ dos indivíduos responderam possuir muita preocupação e somente uma pequena parcela de $10 \%$ afirmaram não se preocupar quanto a essa questão (Figura 6a).

O tratamento de água é a principal maneira de assegura condições ideais a saúde da população. Porém os bons resultados do tratamento somente podem ser assegurados com uma operação hábil e segura (Richter, 1991). Dito isso, indagouse aos moradores sobre a realização de alguma ação de tratamento antes de se beber, como resultado $68 \%$ responderam filtrar a água antes de usa-la e 10\% indicaram não realizar nenhuma ação nesse aspecto (Figura 6b). 


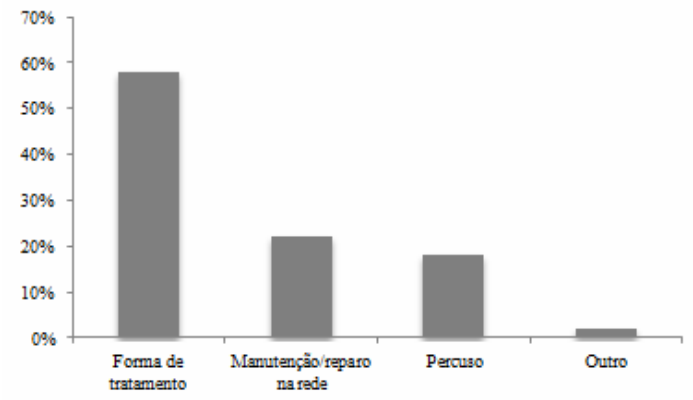

(a)

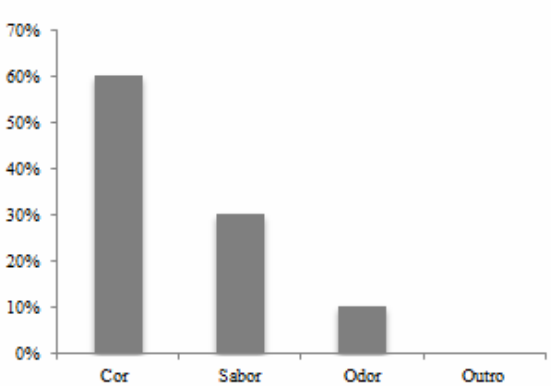

(b)

Figura 5. Fatores importantes de qualidade da água (a) e critérios de qualidade da água (b).

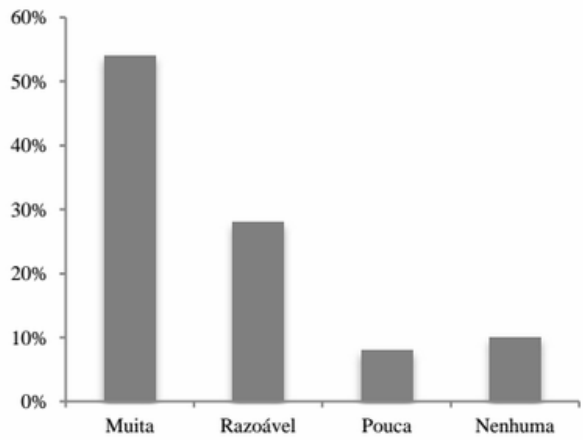

(a)

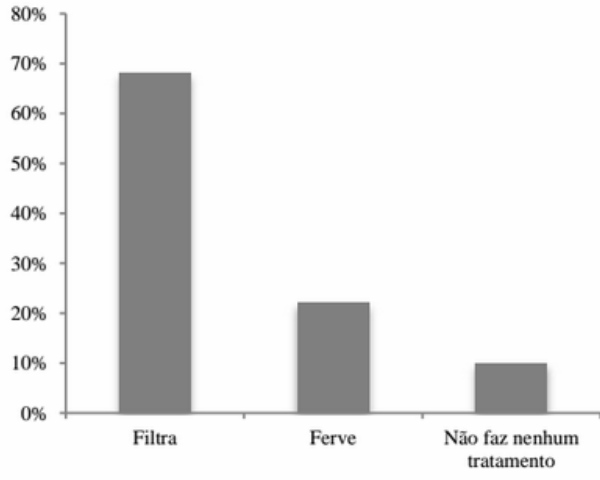

(b)

Figura 6. Grau de preocupação sobre a qualidade da água (a) e tratamento dado água antes de beber (b).

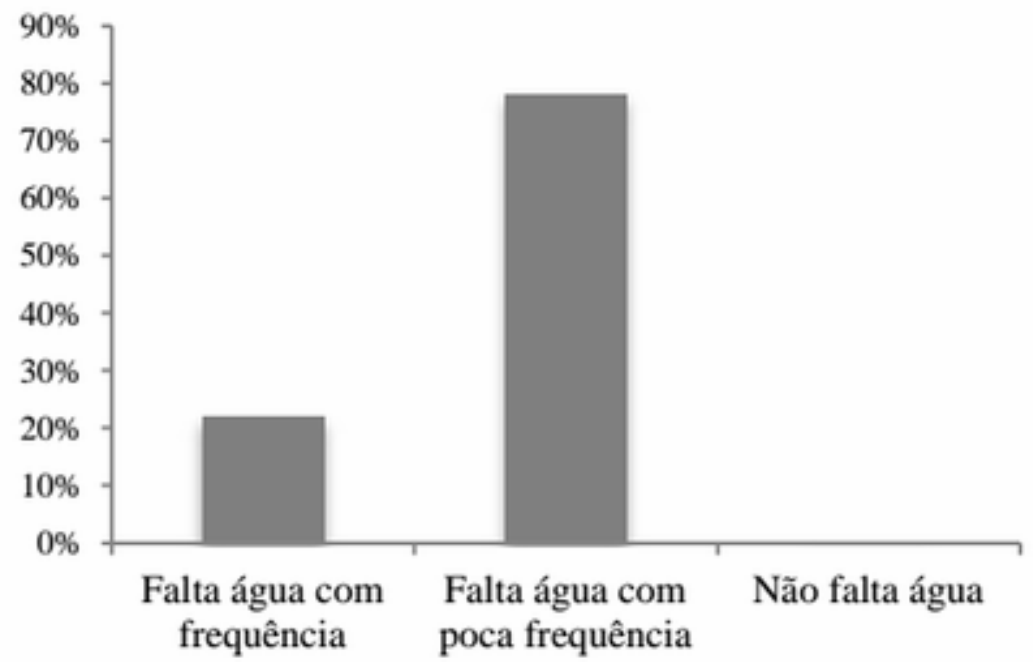

Figura 7. Situação do fornecimento de água para os moradores. 
Os moradores também foram consultados quanto à periodicidade de abastecimento de água no bairro. De acordo com os respondentes $78 \%$ indicaram a falta de água eventualmente, entretanto 22\% afirmaram faltar água frequentemente (Figura 7). Diante disso, apesar da não eventualidade da falta de água ainda sim há preocupações a respeito disso, pelo fato da água ser um recurso essencial a estadia da população diariamente.

\section{Conclusão}

Os resultados das entrevistas indicam que os moradores possuem uma percepção apurada e consciente da qualidade da água, pois estes acreditam que a qualidade da água consumida possui pouca qualidade. Desta forma alguns aspectos de análises da água apontam que, em alguns pontos do sistema de abastecimento esta qualidade água não atende aos padrões de potabilidade, evidenciando 0 questionamento dos moradores quanto o sistema de abastecimento de água que é distribuída ao Bairro Olaria.

\section{Declaração de conflito de interesses}

Os autores declaram não haver conflito de interesses.

\section{Referências}

Brasil. Leis, decretos, etc. Portaria MS n ${ }^{\circ} \mathbf{5 1 8}$, de 25 de março de 2004. Disponível em: $<$ http://www.aeap.org.br/doc/portaria_518_de_2 5_de_marco_2004.pdf $>$. Acesso em: 7 jun. 2015.
Cisneros, B. J.; Tundisi, J. G. Diagnóstico del água em las Americas. Mexico: IANAS/Foro Consultivo Científico y Tecnológico, 2012. Disponível em: <http://www.ianas.org/water/ book/diagnostico_del_agua_en_las_americas.pdf $>$ . Acesso em: 10 jul. 2015.

Cochran, W. G. Técnicas de amostragem. Rio de Janeiro: Fundo de Cultura, 1965.

Freitas, V. P. S. Padrão físico-químico da água de abastecimento público da Região de Campinas. Revista do Instituto Adolfo Lutz, v. 61, n. 1, p. 51-58, 2002.

Libânio, P. A. C.; Chernicharo, C. A. L.; Nascimento, N. O. A dimensão da qualidade da água: avaliação da relação entre indicadores sociais, de disponibilidade hídrica, de saneamento e de saúde pública. Eng. Sanit. Ambiental, v. 10, n. 3, p. 219-228, 2005. Disponível em: <http://www.scielo.br/pdf/esa/ v10n3/a06v10n3>. Acesso em: 10 jul. 2015.

Magalhães, T. Perigo de morte (ou risco de vida). Bio., v. 7, n. 7, p. 4-9, 1995.

Menezes, J. P. C.; Bertossi, A. P. A. Percepção ambiental dos produtores agrícolas e qualidade da água em propriedades rurais. Revista Eletrônica Mestrado em Educação Ambiental, v. 27, p. 1517-1256, 2011. Disponível em: <https://www.seer.furg.br/ remea/article/download/3189/1853>. Acesso em: 10 jul. 2015.

MMA - Ministério do Meio Ambiente. Água: manual de uso: vamos cuidar de nossas águas: implementando o Plano Nacional de Recursos Hídricos. Brasília: MMA, 2009.

Richter, C. A.; Azevedo Netto, J. M. Tratamento de água: tecnologia atualizada. São Paulo: Blücher, 1991.

Informação da Licença: Este é um artigo Open Access distribuído sob os termos da Licença Creative Commons Attribution, que permite uso irrestrito, distribuição e reprodução em qualquer meio, desde que a obra original seja devidamente citada. 